\title{
Barriers to typhoid fever vaccine access in endemic countries
}

This article was published in the following Dove Press journal:

Research and Reports in Tropical Medicine

10 March 2017

Number of times this article has been viewed

\author{
M Imran Khan' \\ Carlos Franco-Paredes ${ }^{2,3}$ \\ Sushant Sahastrabuddhe ${ }^{4}$ \\ R Leon Ochiai ${ }^{5}$ \\ Vittal Mogasale ${ }^{4}$ \\ Bradford D Gessner 6 \\ 'Center of Excellence in Women \\ and Child Health, The Aga Khan \\ University, Karachi, Pakistan; ${ }^{2}$ Hospital \\ Infantil de México, Federico Gómez, \\ México DF., Mexico; ${ }^{3}$ Phoebe Putney \\ Memorial Hospital, Albany, GA, USA; \\ ${ }^{4}$ International Vaccine Institute, \\ Seoul, Republic of Korea; ${ }^{5}$ Sanofi \\ Pasteur, Lyon, ${ }^{6}$ Agence de Médecine \\ Preventive, Ferney-Voltaire, France
}

Correspondence: M Imran Khan Center of Excellence in Women and Child Health, The Aga Khan University, Stadium Road, Karachi, Pakistan Tel +922134985169 ext 8048 Fax +922134934294

Email khan.m.imran@outlook.com

\begin{abstract}
Typhoid vaccines have been available as a means of disease control and prevention since 1896; however, their use as a routine tool for disease prevention in endemic settings has been hampered because of: 1) insufficient data on disease burden particularly regarding the lack of health care access in the poorest communities affected by typhoid; 2) limitations of the typhoid vaccine, such as shorter duration of protection, moderate efficacy in young children, and no efficacy for infants; 3 ) inadequate evidence on potential economic benefits when used for a larger population; 4) neglect in favor of alternative interventions that require massive infrastructure; 5) no financial support or commitment regarding vaccine delivery cost; 6) ambivalence about whether to invest in water and sanitation hygiene versus the vaccine; and 7) clarity on global policy for country adoption. If current typhoid-protein conjugate vaccines live up to their promise of higher efficacy, longer duration of protection, and efficacy in young children, typhoid vaccine use will be a critical component of short- and medium-term disease control strategies. Typhoid control could be accelerated if the global framework includes plans for accelerated introduction of the conjugate typhoid vaccine in developing countries.
\end{abstract}

Keywords: typhoid fever, vaccines, policy, endemic countries, barriers, immunization

\section{Introduction}

Three-fourths of the world's population remains at risk of contracting enteric fever. ${ }^{1}$ Salmonella enterica serovar typhi (S. typhi) and S. enterica serovar paratyphi (S. paratyphi) A and B cause enteric fever, a febrile illness specific to humans. ${ }^{2}$ The genus Salmonella belongs to the family of Enterobacteriaceae and are Gram-negative, nonspore-forming, facultative anaerobic bacilli. ${ }^{3}$ Of the paratyphoid group, $S$. paratyphi A is the most common serovar in Asia, with a few instances when S. paratyphi B strain rates were higher for paratyphoid fever. ${ }^{4,5}$ The other serotype of the Salmonella genus is nontyphoidal Salmonellae, which infect a variety of hosts and are frequently zoonotic. $^{6}$

Typhoid fever, the major contributor to global enteric fever burden, is a systemic infection contracted through the ingestion of contaminated water or food. ${ }^{7,8}$ Prior to the discovery of antibiotics and scaling up of water treatment methods, typhoid fever was a major cause of mortality worldwide. Currently, it remains a significant cause of illness and death in developing countries where access to safe water and basic sanitation is significantly compromised..$^{9-11}$ Asian and African countries report the largest share of global typhoid cases. ${ }^{1,12,13}$ The burden of disease in Asia is well documented, and a recent multinational African study found a significant burden in 


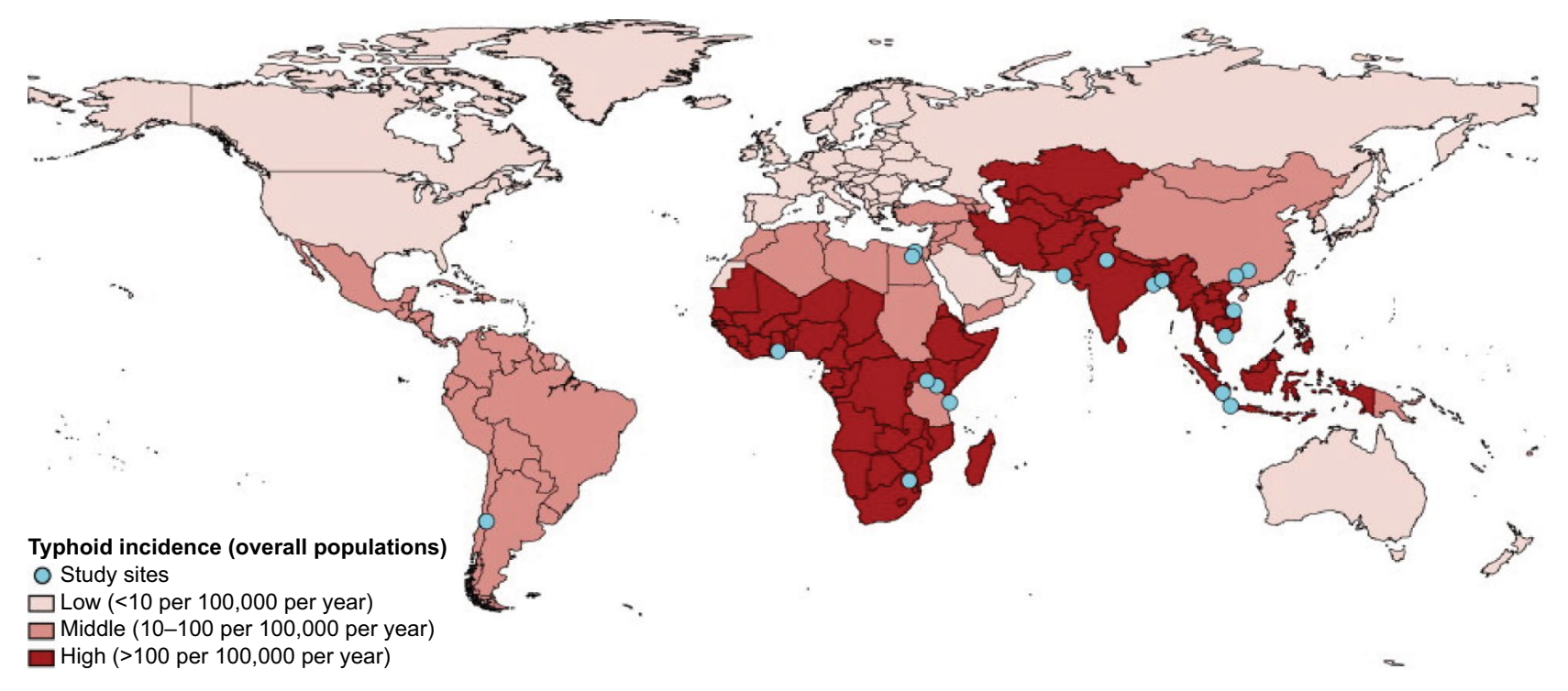

Figure I Burden of typhoid fever in low-income and middle-income countries.

Africa as well. ${ }^{14}$ Children, those between the ages of two and four being the most vulnerable, are at far greater risk in typhoid-endemic countries such as Bangladesh, India, Nepal, and Pakistan. ${ }^{15-17}$ Typhoid and paratyphoid fever incidence rates vary between and within countries from 6/100,000 to $1173 / 100,000$ persons per year (Figure 1). ${ }^{18-20}$ These variations can be explained primarily by differences in access to clean water and sanitation, as well as population prevalence of chronic carriers, baseline immune status, and cultural norms (such as dietary habits). ${ }^{11}$

Typhoid fever can be treated with antibiotics. However, treatment as an alternative to prevention has proven ineffective. Antibiotic resistance has negated the efficacy of many frontline antibiotics. ${ }^{21,22}$ Treatment may not prevent chronic carriage, which, in turn, perpetuates disease transmission. Many people in resource-poor settings do not have ready access to health care services. Finally, delayed treatment can result in fatal disease outcomes, which include intestinal bleeding, intestinal perforation, and neurological complications, such as delirium and hallucination. ${ }^{2,23}$ For these reasons, prevention primarily with vaccines remains preferable to focusing on treatment.

\section{Disease prevention and the role of typhoid vaccines}

The countries where economic development resulted in improved supply of clean drinking water and sanitation facilities have been able to control typhoid fever transmission substantially. ${ }^{24}$ The development of sewage and supplies of piped water in many urban settings decreased the incidence of typhoid fever in the early twentieth century in
North America and Europe. In many countries in Asia and Africa, typhoid is still highly endemic. As witnessed in the past, the control of typhoid fever in endemic countries will continue to be challenged by lack of water and sanitation infrastructural improvements primarily because of the costs involved. ${ }^{25}$ Like all developing countries, lack of financial resources and low prioritization of water and sanitation in typhoid-endemic countries constrain the water, sanitation, and hygiene (WASH) maintenance and expansion. ${ }^{26}$ Lack of accountability, corruption, and inefficient management has hampered the expansion of services, if any, in these countries. Among all the regions that are typhoid endemic, the millennium development goal for safe drinking water and hygiene was not met, an indication of the challenges that these countries face in improving access to WASH. ${ }^{10}$

\section{History of vaccine use}

Vaccination is an effective prevention tool for typhoid fever, especially when coupled with hand washing and household water treatment. ${ }^{27}$ Inactivated phenol-preserved whole-cell typhoid vaccine was developed during the 1890s. Although production was poorly standardized, the vaccine was associated with reduction in typhoid fever incidence in British and US soldiers. ${ }^{28-30}$ Subsequently, the vaccine was used in public health programs in many countries; however, a high level of reactogenicity occurred including fever (up to $30 \%$ of the vaccinees), headache (up to $10 \%$ ), and severe local pain (up to $35 \%$ ), which led to its removal from routine vaccination programs. ${ }^{31-33}$ However, the adverse effects associated with the vaccine and availability of antimicrobial treatment (chloramphenicol) in 1949 affected widespread use of the 
vaccine. ${ }^{34,35}$ In the early 1960 s, when $S$. typhi strains resistant to chloramphenicol were isolated, typhoid vaccine development again garnered interest. ${ }^{36}$ Over time, improved vaccine formulations have become available, including an oral liveattenuated formulation, injectable polysaccharide vaccine, and more recently, injectable typhoid conjugate vaccines with improved safety and efficacy profile..$^{37,38}$

\section{Currently licensed vaccines}

Adverse effects associated with the whole-cell killed vaccine, directed vaccine development efforts at improving the vaccine safety profile. The injectable Vi polysaccharide and oral live-attenuated Ty21a vaccines developed during the 1990s are safe with minimal side effects. The overall protective efficacy for a three-dose regimen of the oral typhoid vaccine ranged between $67 \%$ and $80 \%$ in large-scale efficacy trials, conducted during the $1980 \mathrm{~s}$ in Chile. ${ }^{39-41}$ Two different formulations were tested in typhoid-endemic regions of Indonesia in a randomized, double-blind trial design. ${ }^{42}$ The protective efficacies of the liquid and enteric-coated formulations were $53 \%$ and $42 \%$, respectively. The most common adverse events reported with Ty $21 \mathrm{a}$ were mild and transient gastrointestinal disturbances, followed by general symptoms such as fever. ${ }^{33}$ Only a limited and transient level of shedding in the stools of volunteers was seen with Ty21a and no person-to-person transmission was observed. ${ }^{39}$

The injectable $\mathrm{Vi}$ polysaccharide vaccine is given in a single dose and was found to be well tolerated and to confer $64 \%-72 \%$ protection for $17-21$ months and $55 \%$ over 3 years. The protection conferred and immunological response to the vaccine were consistent both in populations of endemic and nonendemic areas. ${ }^{43-47}$ The most common side effects are pain, redness and induration at injection site, and fever. In very rare cases, allergic reactions and rashes have been observed. ${ }^{48}$

The current World Health Organization (WHO) position paper recommends the programmatic use of typhoid vaccines in endemic areas and for outbreak control. ${ }^{27}$ Despite this, the injectable Vi polysaccharide vaccine has been used in routine immunization programs only in China, Vietnam, and India. ${ }^{49}$ A properly designed randomized trial has not been conducted in these settings. Available government data from China and Vietnam suggest a significant reduction in the burden of typhoid fever in these settings. ${ }^{49}$ While burden reductions could have occurred because of factors other than the vaccine, the concurrent rise in disease caused by $S$. paratyphi, which has the same transmission routes as typhoid, suggests that this was not the case.

Two primary reasons exist for the limited scale of vaccine use including: 1) reduced or no immunogenicity in younger children and infants; and 2) duration of protection only up to 3 years for polysaccharide vaccine and 7 years for oral live vaccine, which, in turn, requires repeat doses and alternative platforms for vaccine delivery. To address these challenges, typhoid conjugate vaccine development was initiated at the US National Institutes of Health (NIH) in the 1980s based on a recombinant vaccine that used exoprotein A from Pseudomonas aeruginosa. The expectation from typhoid conjugate vaccines is that the vaccination of infants and young children will result in protection that endures through the high-risk preschool and school-age years and that it addresses other challenges faced with the improving use of oral and polysaccharide vaccines. ${ }^{50}$ The safety and efficacy data of US NIH typhoid conjugate vaccine were published in $1999 .{ }^{51,52}$ The vaccine is highly immunogenic in young infants, provides long-term protection, and is safe. ${ }^{53}$ Following on the footsteps of US NIH, there are currently 11 manufacturers working on the development of a toxoid conjugate vaccine (TCV) globally (Table 1), including a model of technology transfer to developing country vaccine manufacturers, so that low-cost vaccines are accessible to the populations that would benefit

Table I Pipeline of the development of enteric fever vaccines

\begin{tabular}{|c|c|c|c|c|}
\hline$\overline{M a n}$ & Loc & $\begin{array}{l}\text { Technology } \\
\text { transfer } \\
\text { agreement }\end{array}$ & $\begin{array}{l}\text { Product } \\
\text { details }\end{array}$ & $\begin{array}{l}\text { Clinical } \\
\text { development } \\
\text { status }\end{array}$ \\
\hline $\begin{array}{l}\text { Bharat Biotech } \\
\text { Int. Ltd }\end{array}$ & In & Ow & Vi-TT & $\begin{array}{l}\text { NRA licensure in } \\
\text { India } \\
\text { Submitted for } \\
\text { WHO PQ }\end{array}$ \\
\hline $\begin{array}{l}\text { Bio-Med Pvt. } \\
\text { Ltd }\end{array}$ & India & Own R\&D & Vi-TT & $\begin{array}{l}\text { NRA licensure in } \\
\text { India }\end{array}$ \\
\hline PT BioFarma & Indonesia & IVI & Vi-DT & $\begin{array}{l}\text { Phase I clinical } \\
\text { trial to start in } \\
\text { first quarter } 2017\end{array}$ \\
\hline Finlay Institute & Cuba & Unknown & Vi-DT & start \\
\hline $\begin{array}{l}\text { Lanzhou } \\
\text { Institute } \\
\text { (CNBG) }\end{array}$ & & $\begin{array}{l}\text { US National } \\
\text { Institutes of } \\
\text { Health }\end{array}$ & Vi-rEPA & $\begin{array}{l}\text { NRA licensure } \\
\text { application } \\
\text { submitted }\end{array}$ \\
\hline SK Chemicals & $\begin{array}{l}\text { South } \\
\text { Korea }\end{array}$ & IVI & Vi-DT & $\begin{array}{l}\text { Phase I clinical } \\
\text { trial started May } \\
2016\end{array}$ \\
\hline Incepta & Bangladesh & IVI & Vi-DT & Preclinical stage \\
\hline Biological E & India & NVGH & Vi-CRM & $\begin{array}{l}\text { Phase I clinical } \\
\text { trial }\end{array}$ \\
\hline EuBiologics & $\begin{array}{l}\text { South } \\
\text { Korea }\end{array}$ & Own R\&D & Vi-CRM & $\begin{array}{l}\text { Formulation } \\
\text { ongoing }\end{array}$ \\
\hline Davdc & Vietnam & Own R\&D & Vi-DT & Preclinical stage \\
\hline Walvax & China & Own R\&D & Vi-TT & Preclinical stage \\
\hline
\end{tabular}

Abbreviations: NRA, National Regulatory Authority; R\&D, research and development; Vi-rEPA, Vi recombinant exoprotein antigen; WHO, World Health Organization; CNBG, China National Biotech Group; IVI, International Vaccine Institute; PQ, prequalification; Vi-TT, Vi conjugated with Tetanus Toxoid; Vi-DT, Vi conjugated with Diphtheria Toxoid; NVGH, Novartis Vaccines for Global Health; Vi-CRM, Vi conjugated with Cross reacting material 197. 
most from their production (GlaxoSmithKline and International Vaccine Institute programs). Two vaccine manufacturers in India have acquired a marketing license for a TCV. Both vaccines are sold in the Indian private market. Despite this notable progress, development of a better vaccine will not necessarily result in widespread use and resultant large impact on typhoid burden. For this to occur, many barriers must be overcome as described subsequently.

\section{Scaling up typhoid vaccine use: barriers or facilitators?}

The fundamental knowledge needed to support vaccine introduction or scale-up of any intervention relates to burden of disease, vaccine safety, effectiveness of vaccination, financial implications, value for money invested compared to alternative choices, capacity of immunization systems, and operationalization of a comprehensive communication and advocacy strategy to garner a political will at national and global levels. ${ }^{54}$

\section{Disease burden}

Accurate assessment of typhoid disease burden remains a challenge. ${ }^{13,20}$ In resource-poor areas, health care access may be limited because of lack of referral, transportation, or the ability to pay for services. Once a person arrives at a health care facility, the outcome may not be suspected (e.g., in malaria-endemic areas where all fever is initially considered malaria), staff may not be available to collect a specimen, or blood culture supplies may not be available. In the laboratory, staff may be improperly trained, insufficient blood may be collected, blood culture has imperfect sensitivity and specificity, and patients may already have received antibiotics. Surveillance systems may be limited in scope - for example, focusing on urban areas - and thus not representative, a serious concern for a disease with wide variability in incidence and risk factors over time and place. Surveillance systems may also have imperfect criteria for triggering collection of a blood culture. While fever may be a relatively easy outcome to assess, complications of typhoid, such as intestinal perforation and out-of-hospital death, pose a substantial challenge for surveillance systems.

Advances have been made that address some of the above concerns. Novel diagnostic techniques that are currently being tested (e.g., sero-surveys based on polymerase chain reaction and antibody titers), once in routine practice, may allow for point-of-care documentation of typhoid, allow accurate testing even after antibiotic pretreatment, and improve on blood culture sensitivity. Insurance schemes in some countries have increased health care access. Risk factor-based modeling that extrapolates from one epidemiological setting to another has been used, but it does not present a compelling case for vaccine introduction in a country because of poor availability and representativeness of local data.

Limited and inaccurate disease burden estimates seriously hamper national and international decision-making regarding typhoid vaccine. Ministry of Health and immunization personnel require multisite/multiregion data from within a country to trigger an introduction decision and convince other ministries (i.e., ministry of finance) to finance such endeavors. The distribution of disease within the country and regions is necessary to target groups for vaccination and to choose the optimal vaccination schedule. Documentation of severe disease, complications, and death is necessary for typhoid vaccine to compete with other health care priorities.

\section{Typhoid vaccine safety, efficacy, and effectiveness}

For oral and injectable typhoid vaccines, safety, efficacy, and effectiveness are well documented. These vaccines cannot be given to children below 2 years and revaccination every 3 years (for polysaccharide vaccine) or 5-7 years (for Ty21a vaccine) is necessary. Ineffectiveness in young children and requirement for booster doses limit the public health utility of these vaccines, issues that should be solved by TCV. However, unlike earlier vaccines, a WHO expert consultation in 2014 identified many knowledge gaps for $\mathrm{TCV}$, including lack of clinical efficacy data, especially in $<2$ years of age; immune duration; availability of adequate postlicensure safety data; and lack of demonstration studies to guide public health use. This information is critical for the large-scale use of the vaccine, and its absence has further delayed vaccine introduction.

These issues could be addressed by a multicenter effectiveness study that includes nested immunogenicity assessments and separate trial arms to evaluate effectiveness in young children. The Bill \& Melinda Gates Foundation has recently received requested proposals to conduct just such evaluations. It will take several years for the results to be available and used for decision making.

\section{Economic analyses and vaccine financing}

A major criterion for policy makers in adopting new vaccination is its value for money. Health economic evaluations such as rigorous cost-effectiveness analysis need to be conducted for typhoid conjugate vaccines. The primary reason for the lack of studies is absent data that would inform these 
evaluations, including: 1) unknown duration of protection and level of effectiveness of TCV; 2) ill-defined vaccination strategies; 3) poorly defined incidence for all, severe, and fatal typhoid, as well as the impact of antibiotic resistance on these outcomes; 4) poorly defined impact of typhoid on non-illness outcomes such as school absenteeism and lost work; 5) incomplete cost information such as that for illness, treatment, vaccines, and immunization delivery; and 6) poor understanding of the role of chronic carriers and their impact on disease transmission risk, despite public vaccination. For example, while it is known that the cost of illness per episode of typhoid fever in some settings is the highest for 2-5-year-old children and both hospitalization and antimicrobial resistance increase the cost of illness, data for other settings are lacking. ${ }^{55}$

Financing of typhoid vaccines has been a major bottleneck in country adoption. Many typhoid-endemic countries are low-income ones and eligible for support from Gavi, the vaccine alliance. Gavi, however, has withheld a decision to support the existing typhoid vaccines while waiting for WHO prequalification. ${ }^{56}$ This support window will continue until Gavi determines its next vaccine investment strategy in 2018 where the financing decision will be reevaluated based on other competing uses for funding, including other new vaccines. In most of the new vaccine introductions, financial support from Gavi and strong recommendations from WHO on the need and benefits of vaccine have resulted in public sector vaccine introduction. It is, thus, encouraging that during 2016, WHO started a process of updating its policy recommendations by establishing a working group on typhoid vaccine. ${ }^{57}$ Even if Gavi provides support for vaccination, this will not address all concerns because such funding is restricted to the period during which a country is below a poverty threshold, after which it enters a transition to full country funding of vaccines. As few countries to date have completed full transition, it is uncertain whether this process will lead to countries eliminating some vaccines from public programs. In addition, typhoid may occur in relatively poor areas of non-Gavi-eligible countries, that is not in current global debate for TCV roll out.

\section{Vaccine and programmatic costs}

Vaccine price is a major concern for all vaccines. A lowincome country is unlikely to be able to afford the purchase of new vaccine unless provided with external support, such as through Gavi, despite many of these countries experiencing endemic typhoid. Similarly, Gavi-graduating and middle-income countries may have severely constrained immunization program budgets. It is possible that bulk purchase and pooled procurement mechanisms could lead manufacturers to offer a lower sales price. However, data on this hypothesis are lacking because national and subnational purchase prices are not generally made public. Furthermore, vaccine prices in the past have remained relatively high until multiple manufacturers have entered the market. Even if these mechanisms could lead to lower prices, they require substantial organizational capacity such as that provided by the Pan American Health Organization in Latin America, which has to date been lacking for typhoid vaccine.

With expectation of WHO prequalification, the TCV is on the Gavi priority list for funding considerations until 2018. Once a WHO-prequalified typhoid conjugate vaccine is available, Gavi will likely invite country application for supporting typhoid vaccination. The next Gavi funding window for country support of new vaccines will be the 2019-2023 cycle and TCV will be reevaluated in 2018 for continuation of financing. If Gavi elects to include typhoid vaccine in its investment portfolio, it will still need to come to an agreement with the manufacturers on price.

Beyond vaccines, countries and donors will need to consider the programmatic costs of incorporating typhoid vaccine into public immunization programs. For example, the immunization supply chain and national immunization program staff, space, and infrastructure in many instances are at capacity because of other new vaccine introductions, so adding new vaccines may require new investments.

\section{Vaccine prioritization}

Persons living in developing countries face high infectious disease risk throughout their lifespan, and many of these infectious diseases have become vaccine preventable. Consequently, governments must prioritize which vaccines to introduce and in which order. Numerous factors enter into this decision, including disease burden, outbreak or epidemic potential, impact on health care utilization and disruption, availability of other interventions for disease control, economic implications, availability of external funding (e.g., through Gavi), recommendations from national immunization technical advisory groups, and political considerations.

\section{Preference to incorporate new vaccine into routine Expanded Program on Immunization}

Governments usually have a preference for introducing new vaccines through existing Expanded Program on Immunization (EPI) systems because this minimizes the programmatic 
costs associated with vaccine introduction. Regardless of the typhoid vaccine used, public health programs will likely target persons other than mothers and infants, the traditional target groups for EPI vaccines. For example, in many countries, the peak incidence occurs among persons aged 9-12 years. This reality requires alternative approaches, which, in turn, can increase costs and programmatic challenges.

Despite this, successful examples exist already of vaccine introductions outside of traditional age ranges. If typhoid vaccine were to be delivered during adolescence, immunization program leads could learn from the example of human papillomavirus (HPV) vaccine, which has been delivered through school-based programs and community outreach. If vaccine was delivered in mass campaigns (followed by, e.g., routine infant immunization), lessons could be learned from the successful introduction of yellow fever and serogroup A meningococcal conjugate vaccines in West Africa.

The typhoid fever vaccines have similar challenges to yellow fever, meningitis, and HPV vaccines when it comes to vaccine delivery strategy. The vaccine efficacy below 5 years of age for Vi vaccines is not clear, and the disease distribution is geographic. The introduction in EPI is much easier when a vaccine schedule could be the same as the existing vaccines (pentavalent vaccine introduction). This has not been the case for typhoid so far. The expectation for the conjugate vaccine is that this may be given with the measles vaccines, overcoming the barriers for an alternative plan.

\section{Policy factors: what generates political will? \\ Global: strong and clear recommendations, donor commitment}

There are no current policy recommendations to use conjugate vaccines in the control of typhoid fever. Although other available vaccines are recommended for typhoid control in the WHO position paper, ${ }^{23}$ global policies often do not percolate downwards to regions or countries, to provide clear guidance on a policy framework for vaccine use. Such clarity would support not only country decision-making but also provide donors the information needed to deliver efficient, evidence-based support.

\section{Competing priorities/focus on broader context (e.g., child survival)}

Vaccines have to compete with other health priorities for financing within health ministries, which themselves have to compete with other ministries for financing. Choosing from multiple competing alternative financing choices is complex and often politically charged rather than strictly evidence based. Where an evidence-based approach is used, vaccines usually demonstrate a high return on investment. This is particularly true when the full public health value of a vaccine is tallied. In the case of typhoid vaccines this would include not only direct reduction in morbidity and mortality but indirect protection of unvaccinated persons, reduction in antibiotic use and antibiotic resistant organisms, reduction or elimination of outbreaks and the health care delivery distortions these entail, economic consequences from loss of business or tourism when an outbreak occurs, reduced risk of household impoverishment because of the cost of health care for typhoid, and reduction in health inequities and the moral capital this provides.

\section{Conclusion}

Typhoid fever is a preventable disease. However, it continues to affect many populations across the globe. The highest burden of disease occurs in settings with prevailing low socioeconomic development and insufficient clean water, sewage and water management systems, and sanitary practices as well as other social risk factors, including population displacement, civil strife, and natural catastrophes.

A global strategy to reduce typhoid disease burden needs to consider the introduction of currently available typhoid vaccines, particularly conjugate vaccines. For typhoid conjugate vaccines to have an impact in the short term on disease incidence, vaccination coverage levels will need to reach high levels in at-risk populations - including young children - which, in turn, will require a public program delivered through national immunization programs.

\section{Disclosure}

The authors report no conflicts of interest in this work.

\section{References}

1. Mogasale V, Maskery B, Ochiai RL, et al. Burden of typhoid fever in low-income and middle-income countries: a systematic, literaturebased update with risk-factor adjustment. Lancet Glob Health. 2014;2(10):e570-e580.

2. Parry CM, Hien TT, Dougan G, White NJ, Farrar JJ. Typhoid fever. N Engl J Med. 2002;347(22):1770-1782.

3. Murray P, Rosenthal K, Kobayashi G, Pfaller M. Medical Microbiology. 5th ed. St. Louis, MI: Mosby, Elsevier Science; 2005.

4. Meltzer E, Stienlauf S, Leshem E, Sidi Y, Schwartz E. A large outbreak of Salmonella paratyphi A infection among Israeli travelers to Nepal. Clin Infect Dis. 2014;58(3):359-364.

5. Karkey A, Thompson CN, Thieu NTV, et al. Differential epidemiology of Salmonella typhi and paratyphi A in Kathmandu, Nepal: a matched case control investigation in a highly endemic enteric fever setting. PLoS Negl Trop Dis. 2013;7(8):e2391. 
6. Gordon MA. Invasive nontyphoidal Salmonella disease: epidemiology, pathogenesis and diagnosis. Curr Opin Infect Dis. 2011;24(5):484-489.

7. Khan MI, Ochiai RL, Soofi SB, et al. Risk factors associated with typhoid fever in children aged 2-16 years in Karachi, Pakistan. Epidemiol Infect. 2012;140(4):665-672.

8. Karkey A, Jombart T, Walker AW, et al. The ecological dynamics of fecal contamination and Salmonella typhi and Salmonella paratyphi a in municipal Kathmandu drinking water. PLoS Negl Trop Dis. 2016;10(1):e0004346.

9. WHO/UNICEF Joint Water Supply, Sanitation Monitoring Programme, World Health Organization. Progress on Drinking Water and Sanitation: 2014 Update. Geneva, Switzerland: World Health Organization; 2014.

10. Satterthwaite D. Missing the millennium development goal targets for water and sanitation in urban areas. Environ Urban. 2016;28(1): 99-118.

11. Wright J, Gundry S, Conroy R. Household drinking water in developing countries: a systematic review of microbiological contamination between source and point-of-use. Trop Med Int Health. 2004;9(1):106-117.

12. Crump JA. Updating and refining estimates of typhoid fever burden for public health action. Lancet Glob Health. 2014;2(10):e551-e553.

13. Crump JA, Ram PK, Gupta SK, Miller MA, Mintz ED. Part I. Analysis of data gaps pertaining to Salmonella enterica serotype Typhi infections in low and medium human development index countries, 1984-2005. Epidemiol Infect. 2008;136(4):436-448.

14. von Kalckreuth V, Konings F, Aaby P, et al. The Typhoid Fever Surveillance in Africa Program (TSAP): clinical, diagnostic, and epidemiological methodologies. Clin Infect Dis. 2016;62(Suppl 1):S9-S16.

15. Sinha A, Sazawal S, Kumar R, et al. Typhoid fever in children aged less than 5 years. Lancet. 1999;354(9180):734-737.

16. Brooks WA, Hossain A, Goswami D, et al. Bacteremic typhoid fever in children in an urban slum, Bangladesh. Emerg Infect Dis. 2005;11(2):326-329.

17. Khan MI, Soofi SB, Ochiai RL, et al. Epidemiology, clinical presentation, and patterns of drug resistance of Salmonella typhi in Karachi, Pakistan. J Infect Dev Ctries. 2012;6(10):704-714.

18. Breiman RF, Cosmas L, Njuguna H, et al. Population-based incidence of typhoid fever in an urban informal settlement and a rural area in Kenya: implications for typhoid vaccine use in Africa. PloS One. 2012;7(1):e29119.

19. Srikantiah P, Girgis FY, Luby SP, et al. Population-based surveillance of typhoid fever in Egypt. Am J Trop Med Hyg. 2006;74(1):114-119.

20. Mogasale V, Mogasale VV, Ramani E, et al. Revisiting typhoid fever surveillance in low and middle income countries: lessons from systematic literature review of population-based longitudinal studies. BMC Infect Dis. 2016;16:35.

21. Zaki SA, Karande S. Multidrug-resistant typhoid fever: a review. J Infect Dev Ctries. 2011;5(5):324-337.

22. Neil KP, Sodha SV, Lukwago L, et al. A large outbreak of typhoid fever associated with a high rate of intestinal perforation in Kasese district Uganda, 2008-2009. Clin Infect Dis. 2012;54(8):1091-1099.

23. World Health Organization. Background Document: The Diagnosis, Treatment and Prevention of Typhoid Fever. Vol WHO/V\&B/03.07. Geneva, Switzerland: World Health Organization; 2003.

24. Cutler D, Miller G. The role of public health improvements in health advances: the twentieth-century United States. Demography. 2005;42(1):1-22.

25. Hutton G, Bartram J. Global costs of attaining the millennium development goal for water supply and sanitation. Bull World Health Organ. 2008;86(1):13-19.

26. Montgomery MA, Elimelech M. Water and sanitation in developing countries: including health in the equation. Environ Sci Technol. 2007;41(1):17-24.

27. World Health Organization. Typhoid vaccines: WHO position paper Wkly Epidemiol Rec. 2008;83(6):49-59

28. Hawley PR, Simmons JS. The effectiveness of vaccines used for the prevention of typhoid fever in the United States army and navy. Am J Public Health Nations Health. 1934;24(7):689-709.
29. Siler JF, Dunham GC. Duration of immunity conferred by typhoid vaccine: results of re-vaccination by intracutaneous injection of typhoid vaccine. Am J Public Health Nations Health. 1939;29(2):95-103.

30. Wright AE. Vaccine therapy-its administration, value, and limitations. Proc R Soc Med. 1910;3(Gen Rep):1-38.

31. Wahdan MH, Sippel JE, Mikhail IA, et al. Controlled field trial of a typhoid vaccine prepared with a nonmotile mutant of Salmonella typhi Ty2. Bull World Health Organ. 1975;52(1):69-73.

32. Ivanoff B, Levine MM, Lambert PH. Vaccination against typhoid fever: present status. Bull World Health Organ. 1994;72(6):957-971.

33. Engels EA, Bennish ML, Falagas ME, Lau J. Typhoid fever vaccines. Vaccine. 2000;18(15):1433-1434.

34. Murti BR, Rajyalakshmi K, Bhaskaran CS. Resistance of Salmonella typhi to chloramphenicol. I. A preliminary report. J Clin Pathol. 1962;15:544-551.

35. Woodward TE, Smadel JE. Preliminary report on the beneficial effect of chloromycetin in the treatment of typhoid fever. Ann Intern Med. 1948;29(1):131-134.

36. Hejfec LB, Levina LA, Salmin LB, et al. Controlled field trials of killed oral typhoid and paratyphoid B vaccines and cell-free, chemical aerosol typhoid vaccine. Dev Biol Stand. 1976;33:93-97.

37. Martin LB. Vaccines for typhoid fever and other salmonelloses. Curr Opin Infect Dis. 2012;25(5):489-499.

38. Fraser A, Paul M, Goldberg E, Acosta CJ, Leibovici L. Typhoid fever vaccines: systematic review and meta-analysis of randomised controlled trials. Vaccine. 2007;25(45):7848-7857.

39. Wahdan MH, Serie C, Cerisier Y, Sallam S, Germanier R. A controlled field trial of live Salmonella typhi strain Ty 21a oral vaccine against typhoid: three-year results. J Infect Dis. 1982;145(3):292-295.

40. Levine MM, Ferreccio C, Black RE, Lagos R, San Martin O, Blackwelder WC. Ty21a live oral typhoid vaccine and prevention of paratyphoid fever caused by Salmonella enterica serovar Paratyphi B. Clin Infect Dis. 2007;45(Suppl 1):S24-S28.

41. Levine MM, Ferreccio C, Cryz S, Ortiz E. Comparison of enteric-coated capsules and liquid formulation of Ty21a typhoid vaccine in randomised controlled field trial. Lancet. 1990;336(8720):891-894.

42. Simanjuntak CH, Paleologo FP, Punjabi NH, et al. Oral immunisation against typhoid fever in Indonesia with Ty21a vaccine. Lancet. 1991;338(8774):1055-1059

43. Klugman KP, Gilbertson IT, Koornhof HJ, et al. Protective activity of Vi capsular polysaccharide vaccine against typhoid fever. Lancet. 1987;2(8569):1165-1169.

44. Klugman KP, Koornhof HJ, Robbins JB, Le Cam NN. Immunogenicity, efficacy and serological correlate of protection of Salmonella typhi Vi capsular polysaccharide vaccine three years after immunization. Vaccine. 1996;14(5):435-438.

45. Mirza NB, Wamola IA, Estambale BA, Mbithi E, Poillet M. Typhim Vi vaccine against typhoid fever: a clinical trial in Kenya. East Afr Med J. 1995;72(3):162-164.

46. Sur D, Ochiai RL, Bhattacharya SK, et al. A cluster-randomized effectiveness trial of Vi typhoid vaccine in India. NEngl J Med. 2009;361(4): 335-344.

47. Khan MI, Soofi SB, Ochiai RL, et al. Effectiveness of Vi capsular polysaccharide typhoid vaccine among children: a cluster randomized trial in Karachi, Pakistan. Vaccine. 2012;30(36):5389-5395.

48. Hessel L, Debois H, Fletcher M, Dumas R. Experience with Salmonella typhi Vi capsular polysaccharide vaccine. Eur J Clin Microbiol Infect Dis. 1999;18(9):609-620.

49. Date KA, Bentsi-Enchill AD, Fox KK, et al. Typhoid Fever surveillance and vaccine use - South-East Asia and Western Pacific regions, 2009-2013. MMWR Morb Mortal Wkly Rep. 2014;63(39):855-860.

50. Podda A, Saul AJ, Arora R, et al. Conjugate vaccines for enteric fever: proceedings of a meeting organized in New Delhi, India in 2009. J Infect Dev Ctries. 2010;4(6):404-411.

51. Lin FYC, Ho VA, Khiem HB, et al. The efficacy of a Salmonella typhi $\mathrm{Vi}$ conjugate vaccine in two-to-five-year-old children. $N$ Engl J Med. 2001;344(17):1263-1269. 
52. Kossaczka Z, Lin FY, Ho VA, et al. Safety and immunogenicity of $\mathrm{Vi}$ conjugate vaccines for typhoid fever in adults, teenagers, and 2- to 4-year-old children in Vietnam. Infect Immun. 1999;67(11): 5806-5810.

53. Mai NL, Phan VB, Vo AH, et al. Persistent efficacy of Vi conjugate vaccine against typhoid fever in young children. $N$ Engl J Med. 2003;349(14):1390-1391.

54. Levine OS, Hajjeh R, Wecker J, et al. A policy framework for accelerating adoption of new vaccines. Hum Vaccin. 2010;6(12): 1021-1024.
55. Bahl R, Sinha A, Poulos C, et al. Costs of illness due to typhoid fever in an Indian urban slum community: implications for vaccination policy. J Health Popul Nutr. 2004;22(3):304-310.

56. GAVI Alliance. GAVI Alliance Board Meeting: final minutes. 2011. Available from: http://www.gavi.org/about/governance/gavi-board/ minutes/2011/16-november/. Accessed January 6, 2017.

57. World Health Organization. Immunization, Vaccines and Biologicals: SAGE Working Group on Typhois Vaccines. 2016. Available from: http://www.who.int/immunization/policy/sage/sage_wg_typhoid_ mar2016/en/. Accessed January 6, 2017.

\section{Publish your work in this journal}

Research and Reports in Tropical Medicine is an international, peerreviewed, open access journal publishing original research, case reports, editorials, reviews and commentaries on all areas of tropical medicine, including: Diseases and medicine in tropical regions; Entomology; Epidemiology; Health economics issues; Infectious disease; Laboratory science and new technology in tropical medicine; Parasitology; Public health medicine/health care policy in tropical regions; and Microbiology. The manuscript management system is completely online and includes a very quick and fair peer-review system. Visit http://www.dovepress. com/testimonials.php to read real quotes from published authors. 